\title{
LODO DE ESGOTO COMO FONTE DE MACRONUTRIENTES PARA A CULTURA DO SORGO GRANÍFERO
}

\author{
F.C. OLIVEIRA'; M.O. MARQUES'; P.A. BELLINGIERI' D. PERECIN; \\ ${ }^{1}$ Depto de Tecnologia - FCAVINNESP - C.P. 45 - CEP: 14870-000 - Jaboticabal,SP \\ ${ }^{2}$ Depto de Ciências Exatas - FCAVIUNESP - C.P. 45 - CEP: 14870-000 - Jaboticabal,SP
}

\begin{abstract}
RESUMO: O presente trabalho foi realizado em condiç̃es de casa-de-vegetaçăo com o objetivo de avaliar os efeitos da aplicaç⿰彳亍o de doses de lodo de esgoto (equivalentes a 0, 5, 10 e 20 t/ha), complementadas ou não com nitrogênio e/ou potássio, sobre parámetros de fertilidade do solo, absorç̃o de macronutrientes e produção de matéria seca por plantas de sorgo granifero (Sorghum bicolor L. Moench.) cultivadas em Latossolo Vermelho Escuro. De maneira geral, foi possfvel observar que o lodo de esgoto, através de sua decomposiç̧o no solo, liberou nutrientes para as plantas, refletindo no aumento da produçמ̄o de matéria seca. Entretanto, visando-se atender d̀s necessidades da cultura, fez-se necessária a complementagia com potássio.

Descritores: lodo de esgoto, macronutriente
\end{abstract}

\section{SEWAGE SLUDGE AS NUTRIENT SOURCE FOR SORGHUM}

ABSTRACT: The effectiveness of sewage sludge as nutrient source was studied under greenhouse conditions using a Typic Haplorthor/LE soll and sorghum as a plant test. The levels of sewage sludge corresponded to applications of 0,5 , 10 and 20 tha-1. The parameters evaluated were sorghum dry matter, nutrient uptake and soil fertility. The results showed that the sewage sludge supplies $\mathrm{N}, \mathrm{P}, \mathrm{Ca}, \mathrm{Mg}$ and $\mathrm{S}$ to plants. $\mathrm{K}$ addition to the sewage sludge is necessary to supply the need of the sorghum plant.

Key Words: sewage sludge, nutrient

\section{INTRODUÇÃO}

O lodo de esgoto é um residuo de composição predominantemente orgânica, obtido ao final do processo de tratamento de águas servidas à população. Sua destinação racional se faz necessária diante dos problemas ambientais que podem ser causados pelo seu acúmulo. Nesse aspecto, surge como promissora a sua utilização em solos agrícolas uma vez que, esse material encerra em sua composição consideráveis teores de matéria orgânica e nutrientes. Assim, o Departamento de Agricultura dos Estados Unidos - USDA (1980) reportou que um lodo de esgoto típico contém $4 \%$ de nitrogênio, $2 \%$ de fósforo, $0,4 \%$ de potássio e $25 \%$ de carbono.

Em relação às necessidades das culturas, BUNTING (1963) relatou que os niveis de $\mathrm{N}$ e $\mathrm{P}$ contidos no lodo são adequados. De forma concordante, LINDEN et al. (1983) acrescentaram que a complementação potássica deve ser considerada quando o potássio encontra-se em baixa disponibilidade no solo. Para AYUSO et al. (1992) o lodo de esgoto constitui-se em boa fonte de fósforo proveni- ente, em grande parte, de detergentes (polifosfatos). Esses mesmos autores salientaram que a incorporação de lodo de esgoto aos solos aumenta a quantidade de fósforo disponivel e consequentemente a assimilação desse elemento pelas plantas. CARVALHO \& BARRAL (1981) afirmaram que a decomposição do lodo de esgoto no solo permite um melhor aproveitamento dos nutrientes pelas plantas, em decorrência da lenta liberação dos mesmos através do processo de mineralização da matéria orgânica.

Trabalhos realizados por LESLIE (1970) e MAYS et al. (1973) demonstraram que o crescimento vegetativo e a produção de grãos de várias culturas, em solos tratados com lodo, foram iguais ou superiores aos das mesmas plantas adubadas com fertilizantes minerais nas doses convencionais. CUNNINGHAN et al. (1975), incorporando ao solo lodo de esgoto sem tratamento prévio, obtiveram aumento na produção de grãos de milho, que se relacionou a maior disponibilidade de N, P e K. SABEY et al. (1977) verificaram maior eficiência no desenvolvimento de plantas de trigo cultivadas em solos que receberam lodo de esgoto, misturado 
com restos de madeira, em comparação à fertilização mineral.

Com base no exposto, desenvolveu-se o presente trabalho com o objetivo de avaliar os efeitos da aplicação de doses de lodo de esgoto, complementadas ou não com nitrogênio e/ou potássio, sobre parâmetros de fertilidade do solo, absorção de macronutrientes e produção de matéria seca por plantas de sorgo granífero cultivadas em um Latossolo Vermelho Escuro.

\section{MATERIAL E METODOS}

O presente trabalho foi conduzido em condições de casa-de-vegetação, junto ao Departamento de Tecnologia da Faculdade de Ciências Agrárias e Veterinárias, UNESP/Campus de Jaboticabal,SP.

Utilizou-se de um Latossolo Vermelho Escuro, textura média, cuja análise química, para fins de fertilidade, mostrou as seguintes características: $\mathrm{P}($ resina $)=7 \mu \mathrm{g} / \mathrm{cm}^{3} ;$ M.O. $=1,2 \% ; \mathrm{pH}\left(\mathrm{CaCl}_{2}\right)=$ 4,$1 ; \mathrm{K}=0,02 \mathrm{meq} / 100 \mathrm{~cm}^{3} ; \mathrm{Ca}=0,3 \mathrm{meq} / 100 \mathrm{~cm}^{3}$; $\mathrm{Mg}=0,2 \mathrm{meq} / 100 \mathrm{~cm}^{3} ; \mathrm{H}+\mathrm{Al}=3,8 \mathrm{meq} / 100 \mathrm{~cm}^{3}$; $\mathrm{SB}=0,52 \mathrm{meq} / 100 \mathrm{~cm}^{3}$ e V $=12 \%$.

$\mathrm{O}$ lodo de esgoto, digerido e seco ao ar, em condições de ser empregado como fertilizante, foi obtido junto à ETE de Barueri - SABESP, BarueriSP. Sua composição química parcial foi a seguinte: $\mathrm{N}=2,14 \% ; \mathrm{P}=1,00 \% ; \mathrm{K}=0,24 \% ; \mathrm{Ca}=1,56 \% ; \mathrm{Mg}$ $=0,27 \%$ e $\mathrm{S}=3,49 \%$. Os teores de $\mathrm{K}, \mathrm{Ca}$ e $\mathrm{Mg}$ foram determinados por extração em água-régia, conforme metodologia proposta por LOON (1985), e, no extrato obtido, foram quantificados por espectrofotometria de absorção atômica, conforme metodologia proposta por GORANDER (1979). Os teores de $\mathrm{P}$ e $\mathrm{S}$ foram quantificados nesse mesmo extrato, por fotocolorimetria e turbidimetria, respectivamente. Os teores de $\mathrm{N}$-total, extraídos por digestão sulfúrica à quente, foram determinados através da metodologia descrita por AOAC (1970).

$O$ delineamento experimental adotado foi o de blocos ao acaso. Utilizaram-se de $\mathbf{4 0}$ vasos plásticos de 6 litros de capacidade, distribuídos em 10 tratamentos com 4 repetiçôes. Os tratamentos empregados foram os seguintes: (lodo equivalente a $\mathbf{t}$ ha $-\mathrm{N}-\mathrm{P}_{2} \mathrm{O}_{5}-\mathrm{K}_{2} \mathrm{O}$ equivalentes a $\left.\mathrm{kg} / \mathrm{ha}\right) ; 1$. ( $\mathrm{L}_{0}$ 10-50-50); 2. ( $\left.\mathrm{L}_{\mathrm{o}}-0-0-0\right)$; 3. $\left(\mathrm{L}_{\mathrm{s}}-13-0-40\right)$; 4. $\left(\mathrm{L}_{\mathrm{s}}\right.$ $0-0-0) ; 5 .\left(\mathrm{L}_{10}-0-0-30\right) ; 6 .\left(\mathrm{L}_{10}-0-0-0\right) ; 7 .\left(\mathrm{L}_{20}-0-0\right.$ 10); 8. $\left(L_{20}-0-0-0\right) ; A_{1}\left(L_{s}-13-0-0\right)$ e $A_{2}\left(L_{s}=0-0\right.$. 40).

O material vegetal de cada parcela foi quantificado. A determinação dos teores de $\mathrm{P}, \mathrm{K}, \mathrm{Ca}$, $\mathrm{Mg}$ e $\mathrm{S}$, foi realizada no extrato nitro-perclórico, obtido de acordo com a metodologia proposta por SARRUGE \& HAAG (1974). Os teores de N-total foram determinados de acordo com a metodologia de AOAC (1970).

Obtidos os resultados de cada parâmetro analisado, foram os mesmos agrupados em esquema fatorial ( $4 \times 2$ ) e dois tratamentos adicionais, ou seja, quatro doses de lodo de esgoto (equivalentes a 0,5 , 10 e $20 \mathrm{t} / \mathrm{ha}$ ), dois niveis de complementação, mais dois tratamentos adicionais, envolvendo $5 \mathrm{t} / \mathrm{ha}$ de lodo de esgoto $+\mathrm{N}$ e 5 tha de lodo de esgoto $+\mathrm{K}$. Cabe ressaltar que as complementações minerais foram efetuadas de forma a atender as necessidades da cultura.

\section{RESULTADOS E DISCUSSĀO}

\section{Material Vegetal}

\subsection{Material seco}

De maneira geral, o aumento das doses de lodo de esgoto aplicadas ao solo, exerceu efeitos significativos no sentido de aumentar a produção de matéria seca, conforme se verifica na TABELA 1.

Esses resultados são concordantes com LESLIE (1970), MAYS (1973) e SABEY et al. (1977), os quais salientaram a tendência de aumento da taxa de crescimento vegetativo de algumas culturas em decorrência da utilização de lodo de esgoto. Quanto ao comportamento das complementações minerais, verifica-se que as mesmas não influenciaram o referido parâmetro, exceção feita a complementação dentro da dose 0 tha de lodo, a qual constituiu-se na fertilização mineral propriamente dita.

Isto contradiz as afirmações de LINDEN et al. (1983), quando os mesmos mencionaram a necessidade de complementação potássica em caso desse elemento encontrar-se em baixa disponibilidade no solo. Por outro lado, concorda com BUNTING (1963), quando este afirmou que os teores de $\mathrm{N}$ e $\mathrm{P}$, no lodo, são adequados.

Nas parcelas que receberam complementação mineral, observa-se que a aplicação de lodo de esgoto (20 t/ha) proporcionou produção de matéria seca comparável à obtida com a fertilização mineral recomendada. Essas, por sua vez, foram superiores à aplicação de lodo de esgoto na dose de 5 tha e não diferentes da dose 10 tha.

Empregando-se apenas lodo, verifica-se que o efeito da aplicação de 20 tha foi superior apenas a dose 0 tha. 
A complementação, apenas com $\mathrm{N}$ ou $\mathrm{K}$, quando do emprego de lodo ( 5 t/ha), não resultou em qualquer efeito significativo.

A análise das curvas constantes da Figura 1 permite inferir que o emprego de doses de lodo de esgoto superiores a 20 tha poderia atingir as maiores produções de matéria seca.

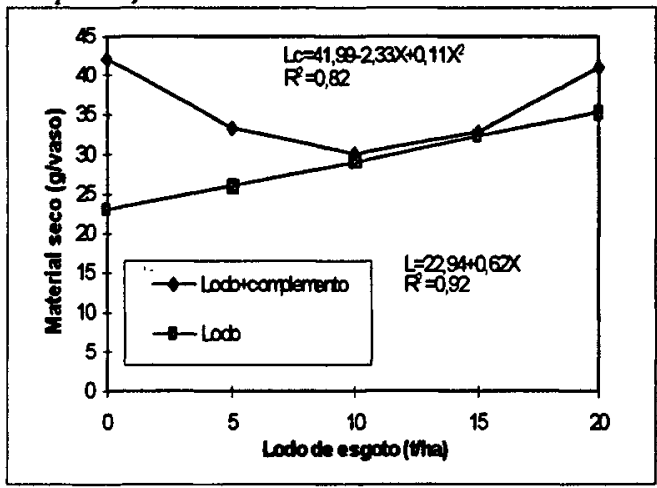

Figura 1 - Material seco produzido por plantas de sorgo. Efeito da complementação mineral de diferentes doses de lodo.

\subsection{Nitrogênio}

A avaliação das quantidades de nitrogênio absorvido pelas plantas indica que o aumento da dose de lodo, aplicado ao solo, proporcionou efeitos significativos na absorção desse elemento. Tais efeitos ocorreram de forma diretamente proporcional, sendo possivel o estabelecimento de uma regressão linear, com aumento da absorção de $\mathrm{N}$ em função das doses de lodo.

Esses resultados são concordantes com CUNNINGHAN et al. (1975), os quais relacionaram a maior disponibilidade de $\mathrm{N}$ no solo em consequência da aplicação de lodo de esgoto.

As quantidades absorvidas de nitrogênio, quando da aplicação exclusiva de 20 tha de lodo, foram superiores aos demais niveis de lodo exclusivos.

No que se refere à realização da complementação mineral, apesar do valor de $F$ (complemento) ter sido significativo, este deve ser considerado com certas restrições, tendo em vista que se baseia em valores médios, os quais acham-se influenciados pela dose 0 tha de lodo de esgoto, que se constitui da fertilização mineral ou apenas solo.

Dessa forma, a não significância da complementação mineral dos tratamentos com lodo de esgoto é visivel através dos desdobramentos estatísticos efetuados.

O comportamento das doses de lodo de esgoto empregadas revela superioridade das parcelas que receberam 20 tha, em relação às demais doses. Esse nível (20 t/ha), quando da realização da complementação mineral, não diferiu da dose 0 tha (fertilização mineral recomendada).

Na Figura 2 verifica-se os comportamentos das quantidades de nitrogênio absorvidas na presença e ausência da complementação mineral do lodo. Da mesma forma que para a produção de matéria seca, aqui também se pode inferir que a aplicação de doses de lodo de esgoto superiores a 20 tha traria aumentos nas quantidades de nitrogênio absorvidas pelas plantas.

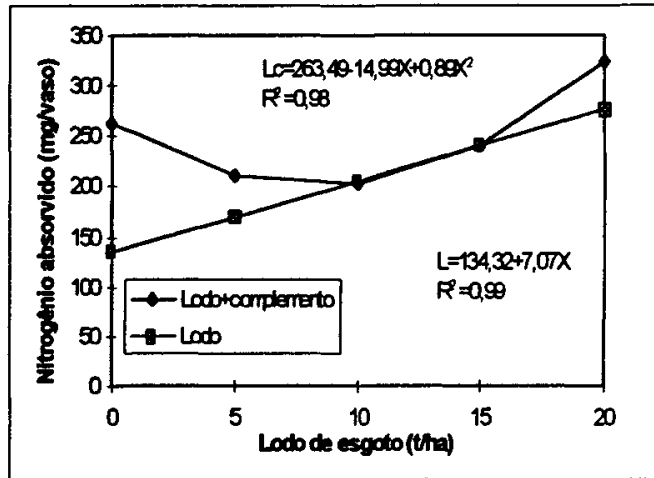

Figura 2 - Absorção de nitrogênio por plantas de sorgo. Efeito da complementação mineral à doses de lodo.

\subsection{Fósforo}

Para o fósforo, verifica-se que o efeito significativo das doses de lodo ocorreu no sentido de favorecer sua absorção. Dessa forma, as quantidades absorvidas com a aplicação de 20 tha de lodo de esgoto foram significativamente superiores às obtidas com as demais doses.

A absorção desse elemento foi diretamente proporcional às doses empregadas, tendo-se estabelecido uma regressão linear para as duas condições (Figura 3).

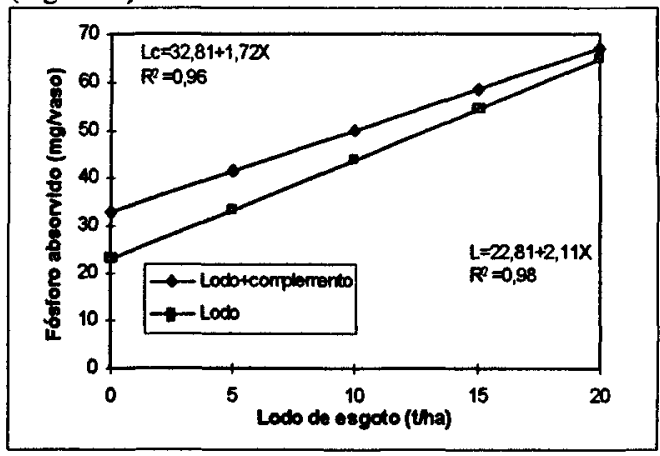

Figura 3 - Absorção de fósforo por plantas de sorgo. Efeito da complementação mineral à doses de lodo. 


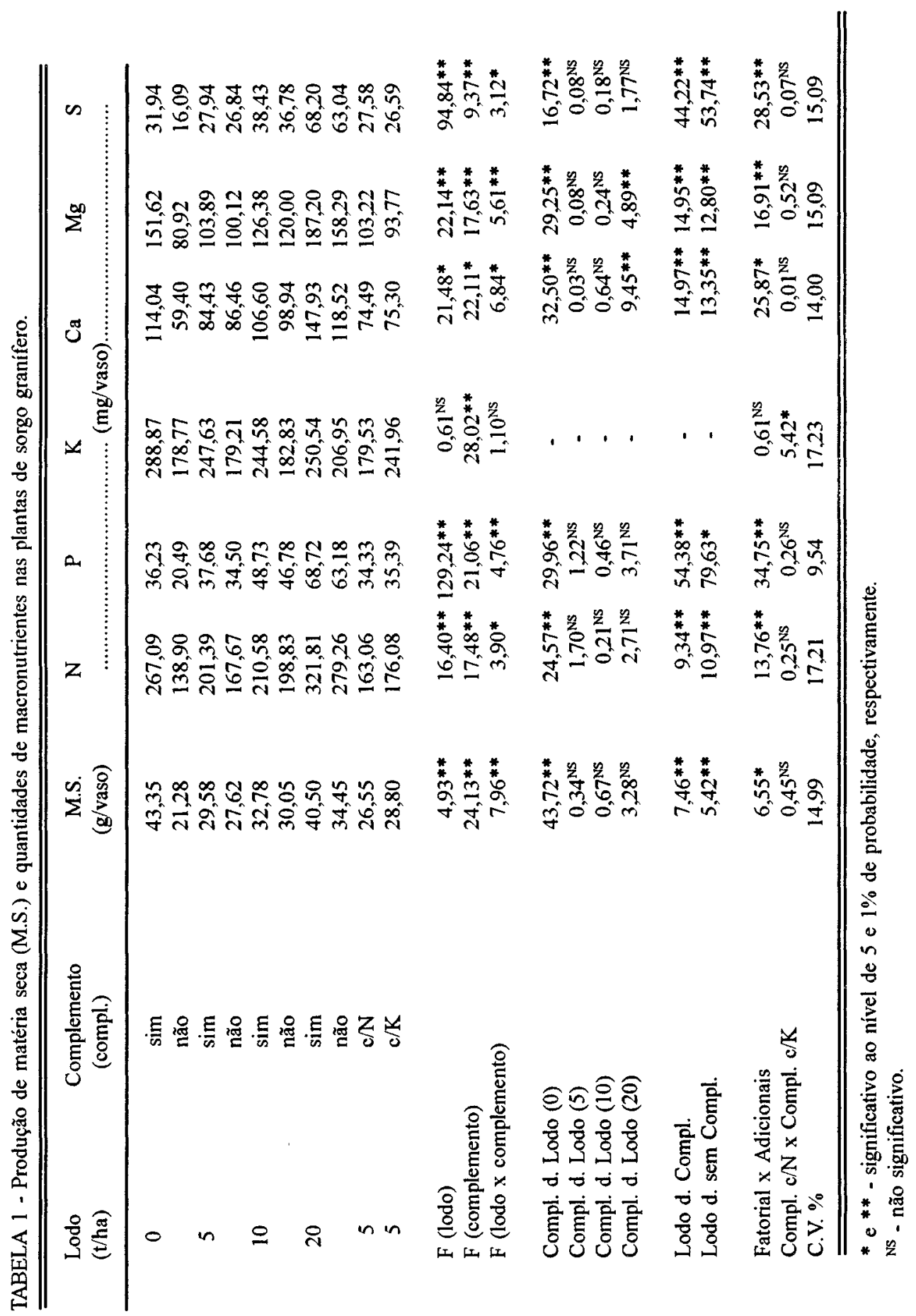


Em termos médios, as doses de lodo proporcionaram quantidades absorvidas de fósforo distintas entre si.

A Figura 3 apresenta o comportamento da absorção de fósforo pelas plantas na ausência e na presença da complementação mineral do lodo de esgoto. A linearidade ascendente dos comportamentos observados, permite sugerir que doses maiores que 20 tha de lodo de esgoto proporcionariam maiores quantidades de fósforo absorvido.

Esse comportamento vai de encontro às afirmações de AYUSO et al. (1992), as quais pressupõem maior absorção desse elemento pelas plantas em decorrência de sua presença, em quantidades satisfatórias, no lodo. Contudo, outros autores como CARVALHO \& BARRAL (1981) salientaram que esta maior disponibilidade é função não só da pura $\mathrm{e}$ simples presença no lodo, mas também decorrente dos efeitos da matéria orgânica nas propriedades químicas do solo.

\subsection{Potássio}

Não houve diferença entre as quantidades absorvidas do elemento em função das diferentes doses de lodo de esgoto.

A superioridade verificada nas parcelas que receberam complementação mineral em relação àquelas que não receberam, bem como daquelas que receberam apenas complementação potássica em relação as parcelas com apenas nitrogênio é evidenciada, não se fazendo necessário maiores comentários.

Se por um lado, em determinadas condições não houve diferença significativa na absorção de potássio, a comparação das condições com complementação e sem complementação mineral deixa bastante nítido que o lodo de esgoto utilizado é um material pobre no referido elemento, sendo sua complementação obrigatória nas doses de lodo testadas no presente trabalho. Isso é concordante com as afirmações de LINDEN et al. (1983), os quais ressaltaram a baixa concentração do lodo em termos de potássio, sendo necessário a sua complementação, visando atender às necessidades das plantas.

Um reforço a essas afirmaçôes, são os leves sintomas de deficiência que foram observados em algumas plantas durante a condução do presente experimento, sugerindo que a fração de potássio oriunda do lodo merece considerações acerca da sua disponibilidade, a qual deve ser dependente do processo de decomposição da matéria orgânica no solo.

\subsection{Cálcio e Magnésio}

A análise de variância para as quantidades médias absorvidas de cálcio e magnésio, indica efeitos significativos das doses de lodo de esgoto. Tais efeitos, para esses elementos, ocorreram de forma proporcional às mesmas.

Especificamente para o cálcio, os totais acumulados apontam para uma superioridade quando do emprego de 20 tha de lodo de esgoto, em relação às demais.

Em relação ao magnésio, as plantas acumularam maior quantidade do elemento quando se empregou 20 tha de lodo. Os resultados obtidos foram significativamente superiores aos demais niveis, os quais não foram diferentes entre si.

O estudo global das complementações minerais sobre a absorção de $\mathrm{Ca}$ e $\mathrm{Mg}$, indica que as mesmas proporcionaram valores maiores, em relação às parcelas que não receberam complementações. Porém, o desdobramento das interações dentro das doses de lodo, apontam efeitos significativos apenas quando se utilizou 20 tha de lodo de esgoto.

Quanto aos efeitos das complementações minerais sobre a absorção desses elementos ( $\mathrm{Ca}$ e $\mathrm{Mg}$ ), os mesmos devem estar associados às relações $\mathrm{KJ}$ $\mathrm{Ca}, \mathrm{K} / \mathrm{Mg}$ e $\mathrm{Ca} / \mathrm{Mg}$. Além do mais, sendo tais elementos absorvidos por fluxo de massa, existe a possibilidade de ocorrência do efeito indireto das complementações minerais as quais aumentariam a disponibilidade de nutrientes, propiciando um maior desenvolvimento vegetativo da planta, intensificando seu metabolismo e, consequentemente, seu potencial de absorção.

As Figuras 4 e 5 apresentam os efeitos das complementações minerais sobre a absorção do cálcio e magnésio.

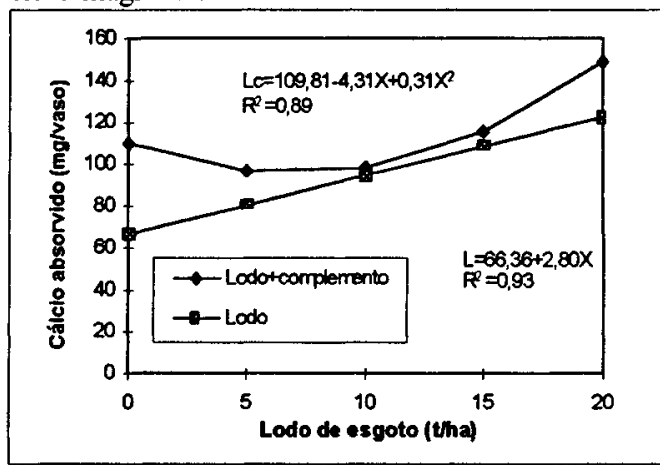

Figura 4 - Absorção de cálcio por plantas de sorgo. Efeito da complementaçăo mineral à doses de lodo. 


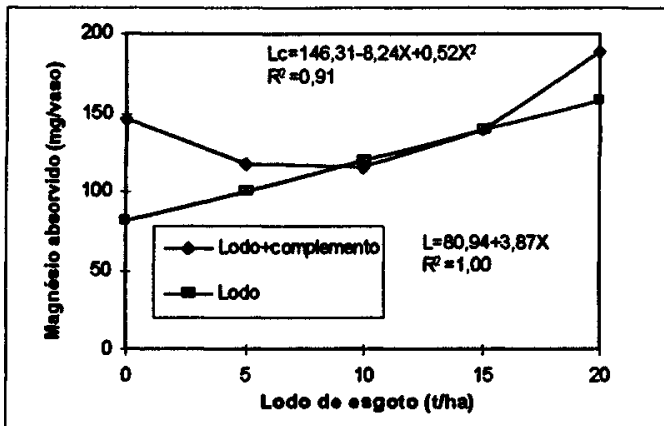

Figura 5 - Absorção de magnésio por plantas de sorgo. Efeito da complementação mineral à doses de lodo.

Da mesma forma que nas análises anteriores, é possível sugerir que o emprego de doses de lodo superiores a 20 tha, resultaria numa maior absorção desses elementos.

\subsection{Enxofre}

Os resultados obtidos para as quantidades absorvidas de enxofre indicam que as doses de lodo exerceram efeitos significativos sobre sua absorçăo. Tais efeitos ocorreram de forma diretamente proporcional às doses de lodo. Assim, os maiores valores encontrados ocorreram quando do emprego de $20 \mathrm{~V}$ ha de lodo de esgoto.

A complementação mineral efetuada, avaliada através dos valores médios dos totais absorvidos para cada dose de lodo, mostrou diferenças significativas, quando comparado com a năo complementação. Entretanto, a análise dos desdobramentos de complementações dentro de doses de lodo permitem melhor visualização, levando-se a concluir que o efeito anteriormente mencionado ocorreu apenas para a dose 0 t/ha de lodo, ou seja, a complementação mineral do lodo não afetou a absorção de enxofre, quando o lodo foi aplicado entre 5 e 20 tha. Este fato pode ser visualizado na Figura 6.

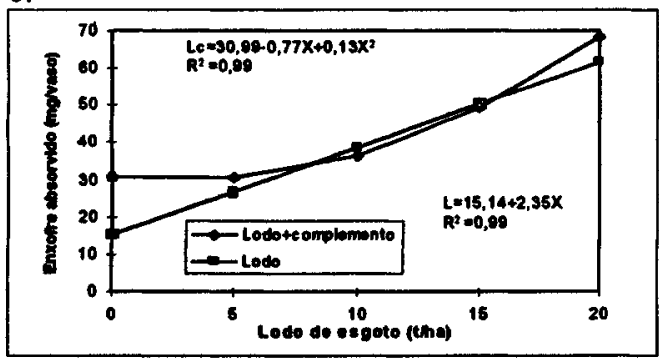

Figura 6 - Absorçåo de enxofre por plantas de sorgo. Efeito da complementação mineral à doses de lodo.

Sci. agric., Piracicaba, 52(2):360-367, mai./ago. 1995
2. Fertilidade do Solo

\subsection{Fósforo}

Os teores de fósforo extraivel do solo são apresentados na TABELA 2.

Pela análise dos resultados, de maneira geral, observa-se que os teores de fósforo no solo aumentaram em funçăo das doses de lodo de esgoto empregadas (Figura 7), reafirmando a possibilidade de se fornecer o referido elemento ao sistema solo-planta, com o emprego de tal resíduo.

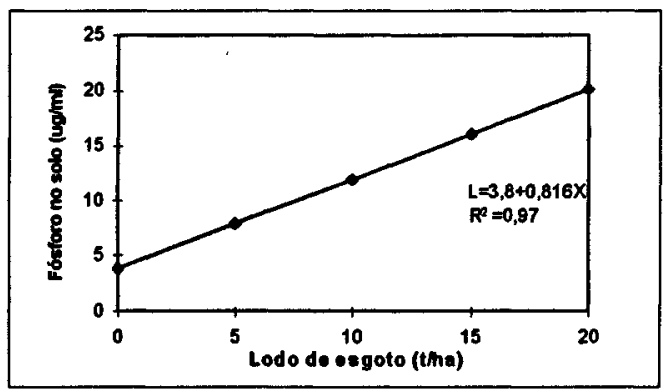

Figura 7 - Fósforo no solo após a colheita do sorgo. Efeito da aplicação de diferentes doses de lodo de esgoto.

O emprego de 20 tha de lodo proporcionou os maiores teores de fósforo. $O$ tratamento que recebeu 10 tha, não diferiu, de forma significativa, do tratamento que recebeu 5 tha de lodo de esgoto. Este último, por sua vez não foi diferente do tratamento em que se empregou 0 tha.

De maneira já esperada, o emprego da complementação mineral não exerceu qualquer efeito sobre os teores residuais de fósforo, visto que, não foi necessária a complementação fosfatada dos tratamentos com lodo de esgoto.

\subsection{Matéria orgânica}

Os teores de matéria orgânica no solo, após a colheita do sorgo, apresentaram um sensivel aumento com o emprego de doses de lodo de esgoto ao solo (Figura 8).

Assim, com base na análise estatística dos resultados, observa-se que, o tratamento em que se empregou 20 tha de lodo, apresentou' maiores teores de matéria orgânica em relaçăo aos demais, os quais não foram diferentes entre si.

\section{3. $\mathbf{H}+\mathbf{A l}$}

O parâmetro $\mathbf{H}+\mathbf{A l}$, após a colheita do sorgo, apresentou uma alteração crescente, em função do emprego das doses de lodo de esgoto. 


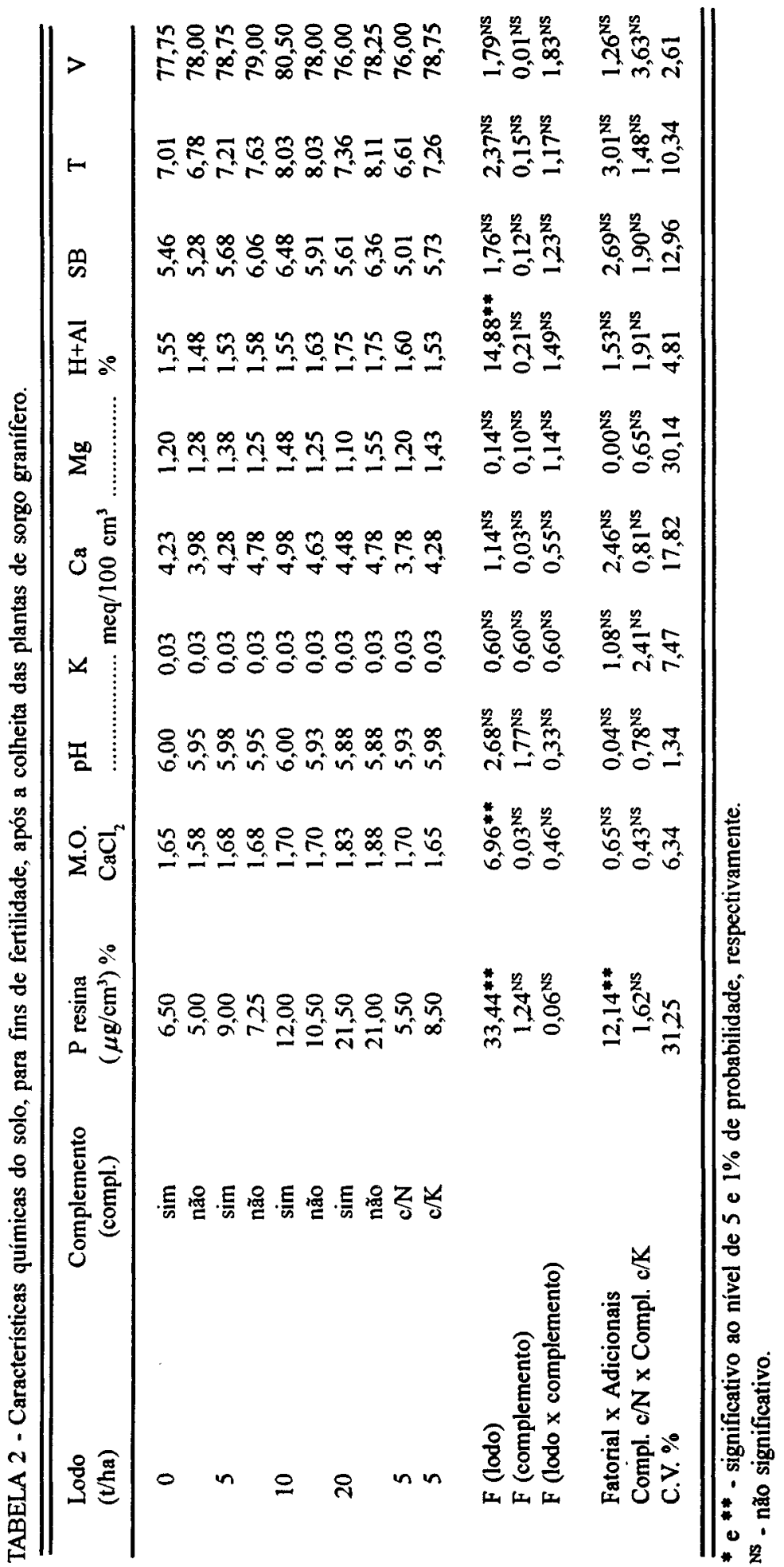




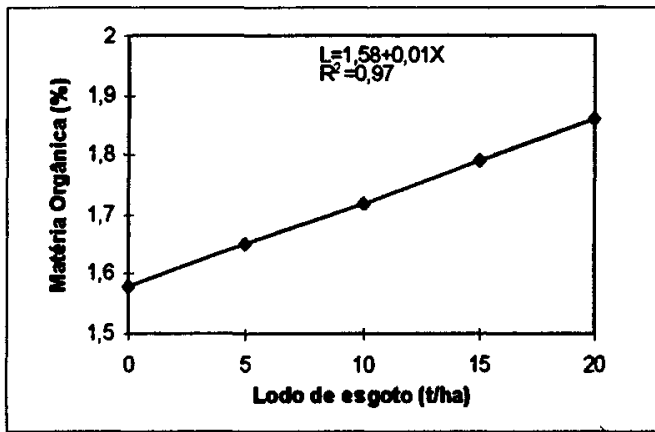

Figura 8 - Matéria orgânica no solo após a colheita do sorgo. Efeito da aplicação de diferentes doses de lodo de esgoto.

Apenas os tratamentos que receberam 20 tha de lodo apresentaram diferenças significativas, quando comparados com os demais. Isso se deve, provavelmente, à presença do alumínio no lodo de esgoto.

\subsection{Outros parâmetros de fertilidade}

Os fatores lodo de esgoto e complementação mineral não apresentaram efeitos significativos, conforme se observa na TABELA 2, para os valores de $\mathrm{pH}\left(\mathrm{CaCl}_{2}\right)$, potássio, cálcio, magnésio, soma de bases, capacidade de troca de cátions e porcentagem de saturação por bases do solo após a colheita do sorgo.

Em relação ao potássio, devido à sua alta solubilidade em água, o mesmo apresenta-se em baixíssimas concentraç̃es no lodo de esgoto, sendo necessária a sua complementação mineral, quando empregado como fertilizante.

Os teores residuais encontrados sugerem que houve um esgotamento do solo, em termos de potássio, colocando todas as parcelas nos mesmos niveis do tratamento correspondente a 0 t/ha, sem complementação mineral.

Quanto aos demais parâmetros, não se esperavam alterações significativas, uma vez que se realizou a calagem do solo em todos os tratamentos.

\section{COŃCLUSŌES}

- Em função de sua composição e de seu comportamento no solo, o lodo de esgoto liberou nutrientes que foram absorvidos pelas plantas de sorgo granifero.

- Visando-se atender às necessidades das culturas, faz-se necessária a complementação do lodo de esgoto com o potássio.

Sci. agric., Piracicaba, 52(2):360-367, mai./ago. 1995
- A aplicação de lodo de esgoto em doses superiores a 20 tha podem proporcionar melhores resultados no desenvolvimento do sorgo granífero.

\section{REFERÊNCLAS BIBLIOGRÁFICAS}

ASSOCIATION OF OFFICIAL ANALYTICAL CHEMISTS. Official methods of analysis of Association of Omial Analytical Chemists. 11.ED. Washington: AOAC, 1970, 1075p.

AYUSO, M.; HERNÁNDEZ, T.; GARCIA, C.; COSTA, F. Utilización de un lodo aerobio como substitutivo de fertilizantes fosforados inorganicos. Suelo y Planta, Madrid, v.2, n.2, p.271-280, 1992.

BUNTING, A.H. Experiments on organic manures. Journal Agriculture of Science, London, v.60, p.121-140, 1963.

CARVALHO, P.C.T.; BARRAL, M.F. Aplicação de lodo de esgoto como fertilizante. Fertilizantes, São Paulo, v.3, n.2, p.1-4, 1981.

CUNNINGHAM, I.D.; KEENEY, D.R.; RYAN, J.A. Yield and metal composition of crop and rye grown on sewage ammended soil. Journal of Environmental Quality, Madison, v.4, p.448-454, 1975.

GORANDER, L. Método de Análise. Varian techtron Pty., 1979, 229p. (Publication, 86.100317-00).

LESLIE, R. Liquid sludges as a farm fertilizer. Compost Sclence, New York, v.11, p.24-25, 1970.

LINDEN, D.R.; CLAPP, C.E.; DOWDOY, R.H. Hydrologic management: nutrients. In: PAGE, AL.; GEASON, T.L.; SMITH, J.E.; ISKANDAR, J.K.; SOMMERS, L.E. (eds.). Utilization of municipal wastewater and sludge on land. Riverside: University of California, 1983.p.79-103.

LOON, J.C.V. Selected methods of trace metal analysis. John Wiley \& Sons, 1985. p.289-291.

MAYS, D.A; TERMAN, G.L.; DUGAN, J.C. Municipal compost: effects on crop yield and soil properties. Journal Environmental of Quality, Madison, v.2, p.89-92, 1973.

SABEY, B.R.; AGBNN, N.N.; MARKSTRON, D.C. Land application of sewage sludge. Joumal Environmental of Quallity, Madison, v.6, p.52-58, 1977.

SARRUGE, J.R.; HAAG, H.P. Análises químicas em plantas. Piracicaba: ESALQ/USP, 1974. 56p.

USDA. United States Department of Agriculture. Report and Recommendations on organic farming. Washington: US. Government, 1980. 94p.

Recebido para publicaçáo em 25.10 .94

Aceito para publicação em 20.07.95 